TITLE:

\title{
Timing and propagule size of invasion determine its success by a time-varying threshold of demographic regime shift
}

\section{$\operatorname{AUTHOR}(S):$}

Yamamichi, Masato; Yoshida, Takehito; Sasaki, Akira

\section{CITATION:}

Yamamichi, Masato ...[et al]. Timing and propagule size of invasion determine its success by a time-varying threshold of demographic regime shift. Ecology 2014, 95(8): 2303-2315

\section{ISSUE DATE:}

2014-08

URL:

http://hdl.handle.net/2433/192888

RIGHT:

(C) 2014 by the Ecological Society of America 


\title{
Timing and propagule size of invasion determine its success by a time-varying threshold of demographic regime shift
}

\author{
Masato Yamamichi, ${ }^{1,5}$ Takehito Yoshida, ${ }^{2}$ and Akira Sasaki ${ }^{3,4}$ \\ ${ }^{1}$ Department of Ecology and Evolutionary Biology, Cornell University, Ithaca, New York 14853 USA \\ ${ }^{2}$ Department of General Systems Studies, University of Tokyo, 3-8-1 Komaba, Meguro, Tokyo 1538902 Japan \\ ${ }^{3}$ Department of Evolutionary Studies of Biosystems, Graduate University for Advanced Studies, Hayama, Kanagawa 2400193 Japan \\ ${ }^{4}$ Evolution and Ecology Program, International Institute for Applied Systems Analysis, A-2361, Laxenburg, Austria
}

\begin{abstract}
Theory of invasion ecology indicates that the number of invading individuals (propagule size) and the timing of invasion are important for invasion success. Propagule size affects establishment success due to an Allee effect and the effect of demographic stochasticity, whereas the timing of invasion does so via niche opportunity produced by fluctuating predation pressure and resource abundance. We propose a synthesis of these two mechanisms by a time-varying dose-response curve where the dose is propagule size and the response is establishment probability. We show an example of the synthesis in a simple predator-prey model where successful invasion occurs as a demographic regime shift because of the bistability of the system. The two mechanisms are not independent, but simultaneously determine invasion success in our model. We found that positive growth rate of an invading species does not ensure its establishment, especially when its propagule size is small or when its growth rate is in a decreasing trend. We suggest the difficulty of understanding invasion process based on a dose-response curve of propagule size as no unique curve can be determined due to the effects of invasion timing (i.e., the threshold of demographic regime shift is time varied). The results of our model analysis also have an implication on the phase relationship between population cycles of predators and prey.

Key words: Allee effect; alternative stable states; antiphase cycles; bistability; eco-evolutionary dynamics; evolutionary cycles; fluctuating resource; invasibility; limit cycles; niche opportunity; propagule pressure; rapid evolution.
\end{abstract}

\section{INTRODUCTION}

Colonization is one of the key concepts in ecology, as it plays a central role in the formation of new communities in novel habitats such as oceanic islands (MacArthur and Wilson 1967, Chase 2003, Fukami et al. 2007). Biological invasion of exotic species is a major threat to biodiversity, thus understanding causes and consequences of invasion is a central topic in conservation ecology. In spite of the large numbers of introduced species, interestingly, comparatively few become successful as invaders according to a global meta-analysis of animals and plants (Williamson and Fitter 1996). Invasion success of new species is affected by various factors, but most studies to date have focused either on invader's traits (Godoy et al. 2011) or native community structures (Fridley et al. 2007, Baiser et al. 2010; note that we use the term invasion success here as establishment/settlement success of invading populations, regardless of demographic trends of native species). Recently, increasing evidence indicates that the number of individuals invading the new environments (propa-

Manuscript received 8 August 2013; revised 2 December 2013; accepted 23 December 2013; final version received 14 January 2014. Corresponding Editor: B. E. Kendall.

5E-mail: my287@cornell.edu gule size; Lockwood et al. 2005, Simberloff 2009) and invasion timing (Davis et al. 2000, Shea and Chesson 2002) are important when considering the invasion process in the context of population dynamics.

The propagule pressure hypothesis posits that the number of individuals released into a region to which they are not native (propagule size) determines invasion success. Several mechanisms have been proposed to explain this pattern, and the most common explanation is that high propagule size can result in the higher growth rate due to an Allee effect (positive density dependence; Taylor and Hastings 2005, Drake and Lodge 2006) and the effects of demographic stochasticity. In addition, it can provide higher genetic variation that will promote adaptation to novel environments (Simberloff 2009). To understand the role of propagule size on invasion success, researchers have tried to reveal the shape of the dose-response curve where the dose is propagule size and the response is establishment probability (Lockwood et al. 2005). The propagule pressure hypothesis also emphasizes the importance of the rate, at which propagules arrive per unit time (propagule number) to diminish impacts of environmental stochasticity (Simberloff 2009), but no study has considered the propagule size and invasion timing simultaneously. 
The fluctuating resource hypothesis proposes that environmental fluctuations temporarily reduce competition intensity, thereby promoting invasion (Davis et al. 2000). The hypothesis has been influential as it can potentially integrate the existing hypotheses regarding community invasibility (Davis et al. 2000). For example, high-diversity communities are resistant to species invasion because diverse communities can reduce resource availability for invading species and lower its invasion success by the resident species' complementary resource use. A few theoretical studies have found that invasion timing matters when resource availability is affected by exogenous (external) environmental fluctuations (Namba and Takahashi 1993, Schoolmaster and Snyder 2007). In addition to resource oscillations, Shea and Chesson (2002) considered the role of fluctuating predation pressure and proposed a unified conceptual framework of niche opportunities. In the framework, the demographic success of an invader is thought to be largely affected either by resource availability or the abundance of its predators. Therefore, large fluctuations in either resources or the predator populations can make the system temporarily vulnerable to invasion (Shea and Chesson 2002).

Although there have been several attempts to propose a unified hypothesis for invasion, it is still challenging to understand interactions of various processes (Fridley et al. 2007, Catford et al. 2009). Ecological studies focusing on the effects of propagule size or invasion timing have been increasing (e.g., Li and Stevens 2012, Allington et al. 2013), but to our knowledge no study has synthesized the two important hypotheses. We propose a possible synthesis of the propagule size and niche opportunity hypotheses by a time-varying threshold of demographic regime shift, which we refer to the temporal change in the threshold density of a demographic regime shift, a conspicuous jump from one stable condition to another (Scheffer et al. 2001). We show an example of the synthesis in a simple predator-prey model where successful invasion occurs as a demographic regime shift. Previous studies underlined the importance of a demographic regime shift including an Allee effect on biological invasion (Taylor and Hastings 2005, Drake and Lodge 2006), but a time-varying threshold of demographic regime shift has been overlooked so far (K. Suzuki and T. Yoshida, unpublished manuscript). Given that mechanisms that generate an Allee effect include predator avoidance and cooperative foraging and that predation pressure and resource availability often fluctuate temporally (Shea and Chesson 2002), a time-varying Allee effect can be potentially common. If there is a strong demographic Allee effect that varies temporally, both propagule size and timing of invasion are not independent, but rather simultaneously determine invasion success.

Establishment of new species with an Allee effect can be regarded as a demographic regime shift (Takimoto 2009). With alternative stable states (ASS), or multi- stability of ecosystems (i.e., coexistence of several locally stable states), community dynamics depend not only on current environments but also on past histories (i.e., hysteresis) and can cause catastrophic regime shifts (Scheffer et al. 2001, Beisner et al. 2003). Accumulating empirical examples indicate that ASS is a common phenomenon in real ecosystems, thus applying the ASS concept to conservation and restoration ecology is becoming significant (Scheffer et al. 2001, Beisner et al. 2003). We focus on the role of various ASS with limit cycles in invasion processes. Theory on food web dynamics has mainly concentrated on equilibrium dynamics that can be solved analytically, and as a result, important dynamics have often been overlooked (Abrams 1999). Because roughly one-third of populations show cyclic dynamics (Kendall et al. 1998) and the top-down effect by predators is a major driver of community dynamics (Hairston et al. 1960, Holt 1977, Noonburg and Byers 2005), it is important to consider biological invasion in nonequilibrium predator-prey dynamics (Vandermeer 2006). We found that ASS with limit cycles can highlight the importance of integrating the niche opportunity and propagule size hypotheses in biological invasion.

We also discuss the implication of the result focusing on invasion timing and antiphase cycles (so-called evolutionary cycles), which are regarded as evidence of rapid evolution of prey defense (Yoshida et al. 2003). This result highlights the importance of introduction timing of genetic variation in eco-evolutionary feedbacks, another frontier in ecology and evolutionary biology (Matthews et al. 2011, Schoener 2011).

\section{Model}

We adopt a diamond food web (one-predator-twoprey-one-resource) model assuming the Holling type II functional response for resource/prey uptake (Yoshida et al. 2007, Yamamichi et al. 2011, Klausmeier and Litchman 2012). This model considers two prey phenotypes differing in their defense ability against predators and also in their resource uptake rates due to trade-off. An undefended (competitive) type is easy to be eaten but rapidly grows, and a defended type is seldom eaten but slowly grows (Meyer et al. 2006, Becks et al. 2010). We adopt the chemostat model, in which resource dynamics is explicitly represented, but a different model with phenomenological logistic growth of prey gives the similar results as the chemostat model (Appendix A: Figs. A1-A5). Many theoretical studies have focused on the diamond food web model (Kretzschmar et al. 1993, Holt et al. 1994, Leibold 1996, McPeek 1996, Grover and Holt 1998, Noonburg and Byers 2005) to understand the complicated interactions between direct resource competition and apparent competition due to predation (Holt 1977). Their general conclusion is that coexistence of two prey species can occur if there is a trade-off between growth and defense and if resource level is intermediate. When resource is scarce, more 
competitive prey will exclude defended prey because resource competition is the dominant interaction, whereas defended prey can beat competitive prey at high resource levels as apparent competition is dominant (Klausmeier and Litchman 2012). The time changes in the concentration of resource, $R$, the density of undefended and defended prey, $N_{1}$ and $N_{2}$, and the density of predator, $P$, are

$$
\begin{aligned}
& \frac{d R}{d t}=\delta\left(R_{\mathrm{I}}-R\right)-\frac{1}{\varepsilon_{1}} \sum_{i=1}^{2} \frac{c_{i} R N_{i}}{1+h_{1} c_{i} R} \\
& \frac{d N_{i}}{d t}=N_{i}\left[\frac{c_{i} R}{1+h_{1} c_{i} R}-\frac{1}{\varepsilon_{2}}\left(\frac{s_{i} P}{1+h_{2} \sum_{j=1}^{2} s_{j} N_{j}}\right)-\delta\right] \\
& \frac{d P}{d t}=P\left[\frac{\sum_{j=1}^{2} s_{j} N_{j}}{1+h_{2} \sum_{j=1}^{2} s_{j} N_{j}}-(\delta+m)\right]
\end{aligned}
$$

Here $\delta$ is dilution rate, $R_{\mathrm{I}}$ is inflow resource concentration, $c_{i}$ is undefended/defended prey capturing efficiency for resource, $h_{1}$ is prey handling time for resource, $s_{i}$ is predator capturing efficiency for undefended/defended prey, $h_{2}$ is predator handling time for prey, $m$ is predator death rate, $\varepsilon_{1}$ is prey assimilation efficiency, $\varepsilon_{2}$ is predator assimilation efficiency, and $i=1$ or 2 . Here $\delta$ and $R_{\mathrm{I}}$ are adjustable parameters of the chemostat system; resource is continuously added to the system and all components are removed from the system at the dilution rate $\delta$.

We assume that capturing efficiency parameters of prey $\left(c_{i}\right)$ and predator $\left(s_{i}\right)$ are positively correlated (i.e., there is a trade-off between defense and growth in prey). Considering the empirical data of Fussmann et al. (2000), we assume the trade-off relationship as

$$
\frac{c_{i}}{\hat{c}}=\left(\frac{s_{i}}{\hat{s}}\right)^{\alpha}
$$

where $\hat{c}$ and $\hat{s}$ are empirically measured constants, and $\alpha$ is a positive constant. This function is formulated so that it always crosses the observed point $(\hat{c}, \hat{s})$ and the origin. We can make the function convex or concave by changing $\alpha$. The capturing efficiency of undefended prey $\left(c_{1}\right)$ is set to 1 . We assumed the linear trade-off $(\alpha=1)$ for the results described in Results and Discussion, but investigated the effects of various trade-off curves (Appendix B: Fig. B1), as our previous study revealed that the concave trade-off $(\alpha>1)$ resulted in broader bistable regions in the phase diagram (Yamamichi et al. 2011).

\section{Analysis}

A bifurcation analysis by numerical continuation of equilibria was conducted using the software XPPAUT (Ermentrout 2002) and simulations to find multiple attractors. We concentrate on bifurcation along three parameters: dilution rate $\delta$, inflow resource concentration $R_{\mathrm{I}}$, and capturing efficiency of defended prey $c_{2}$. The first two parameters are experimentally manipulatable (Fussmann et al. 2000). The bifurcation diagram along inflow resource concentration $\left(R_{\mathrm{I}}\right)$ is of special interest because enrichment has caused regime shifts in many ecosystems (Scheffer et al. 2001). We chose $c_{2}$ as another bifurcation parameter because the similarity between undefended and defended prey is the key to bistability (Yamamichi et al. 2011). Other parameters were fixed as $h_{1}=0.303 \mathrm{~d}, h_{2}=0.444 \mathrm{~d}, m=0.055 \mathrm{~d}^{-1}, \hat{c}$ $=0.767 \mathrm{~d}, \hat{s}=0.15 \mathrm{~d}, \varepsilon_{1}=1.0, \varepsilon_{2}=0.25$, and $\alpha=1.0$ according to the previous experiments on a plankton (rotifer-algal) chemostat system (Fussmann et al. 2000, Yamamichi et al. 2011). To study the relationship between timing and invasion success, we ran numerical simulations and examined the fate of invasion of defended prey to the native community with undefended prey and predator (or the fate of invasion of undefended prey to the community with defended prey and predator). We also analyzed the basin of attraction by randomly choosing combinations of initial values for simulations and examined resultant dynamics. We reduced the dimension of Eq. 1 by excluding resource $(R)$ from dynamics, assuming that the system approaches to the quasi-stable equilibrium and $m=0$ as the estimated predator mortality is negligibly small relative to the dilution rate (the sum of scaled four variables then converges to 1 because $d\left(R^{\prime}+N_{1}^{\prime}+N_{2}^{\prime}+P^{\prime}\right) / d T=1-\left(R^{\prime}\right.$ $\left.+N_{1}^{\prime}+N_{2}^{\prime}+P^{\prime}\right)$, where $R^{\prime}=R / R_{\mathrm{I}}, N_{1}^{\prime}=N_{1} /\left(\varepsilon_{1} R_{1}\right), N_{2}^{\prime}=$ $N_{2} /\left(\varepsilon_{1} R_{1}\right), P^{\prime}=P /\left(\varepsilon_{1} \varepsilon_{2} R_{\mathrm{I}}\right)$, and $T=\delta t$; see Appendix of Yamamichi et al. 2011). Then we randomly assigned initial values from two-dimensional space (predator and undefended prey) while the introduced (initial) number of defended prey was fixed. To assess the validity of the quasi-equilibrium assumption, we compared the result to that of the full model (Eq. 1; Appendix C: Fig. C1).

\section{Results}

\section{Invasion timing, propagule size, and settlement success}

Consider a native community that consists of predator and undefended prey showing limit cycles in their abundances. If defended prey is introduced into the community, invasion success depends on the phase of the limit cycle as well as the number of introduced individuals (propagule size; Fig. 1). This situation, where exotic prey is more defended against predator than native prey, fits the enemy release hypothesis (Catford et al. 2009), but we also analyzed the case where undefended prey is exotic species and defended prey is native species (see Results: Multistability, Appendix A: Fig. A4, Appendix D: Fig. D3). When 

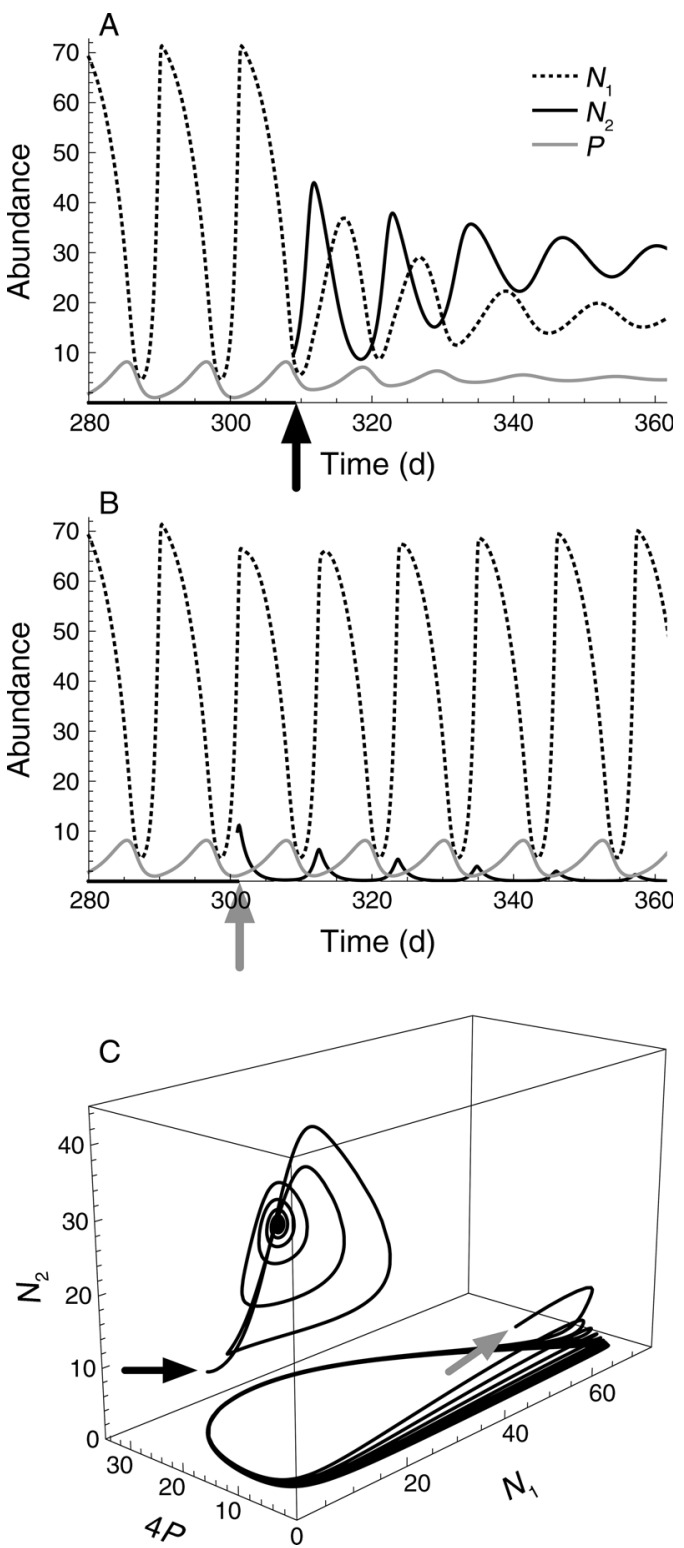

FIG. 1. Timing of invasion determines its success. (A) Invasion success of defended prey introduced at time $t=309$ (black arrow), where $t$ is days. (B) Invasion failure of defended prey introduced at $t=301$ (gray arrow), where $t$ is days. Gray lines show predator $(P)$; black dotted lines show undefended prey $\left(N_{1}\right)$; black solid lines show defended prey $\left(N_{2}\right)$. Introduction abundance of defended prey $\left(N_{2, \text { intro }}\right)$ is 10 in panels (A) and (B). (C) Bistability between the stable coexistence equilibrium with three species and the limit cycle with undefended prey and predator. The $x$ - and $y$-axes are four times predator density $(4 P)$ and undefended prey density $\left(N_{1}\right)$, respectively, and the $z$-axis is defended prey density $\left(N_{2}\right)$. Black and gray arrows represent the invasion timings shown in panels $\mathrm{A}$ and $\mathrm{B}$, respectively. Parameter settings are $c_{2}$ (defended prey capturing efficiency for resource $)=0.3, \delta$ (dilution rate $)=1.5$, and $R_{\mathrm{I}}$ (inflow resource concentration) $=80$. the predator is abundant, the resource is also becoming abundant due to a trophic cascade (Hairston et al. 1960), and thus resource competition is not intense. Together with this and the fitness advantage due to antipredator defense, the defended prey has a higher fitness and can increase (Fig. 1A). As a result, the system moves to the other locally stable coexistence equilibrium (Fig. 1C). On the other hand, if the defended prey is introduced when the predator is scarce, defense is not adaptive and intense resource competition results in the extinction of the defended prey (Fig. 1B). This occurs because of the bistability of the system. In this case there are two locally stable states (attractors): one is a stable coexistence equilibrium with three species, and the other is a stable limit cycle with undefended prey and predator. For a fixed number of introduced individuals, the system moves to one of the attractors depending on the introduction timing of defended prey (Fig. 1C). The per capita growth rate (fitness) of defended prey ((1/ $\left.N_{2}\right)\left(d N_{2} / d t\right)$ ) when it is rare almost keeps in phase with resource and out of phase with undefended prey (Fig. 2A). This indicates that predator-prey limit cycles can temporally create an invasibility window (i.e., niche opportunity sensu Shea and Chesson [2002]) for invading prey.

Not only invasion timing, but also the number of introduced individuals (propagule size), is important for invasion success in our model. When the number of invading individuals is sufficiently large, the introduction of exotic prey can lead the community to cross the border into another basin of attractions, and the system is attracted toward the coexistence equilibrium (Fig. 2D). When the number of introduced individuals is too small, on the other hand, invasion always fails regardless of its timing, and the system stays in the locally stable limit cycles with native species: the timing of invasion corresponds to the point (phase) of the limit cycle of native species, and invasion always fails regardless of its timing because no black points appear on the limit cycle in Fig. 2C. It is interesting that the region where the per capita growth rate of rare defended prey is positive (Fig. 2B) does not always overlap with the region where invasion is successful (Fig. 2C, D). Even if the per capita growth rate is positive at the moment when defended prey is introduced, it fails to establish when the growth rate of defended prey is in a decreasing trend. On the other hand, when the growth rate is temporally increasing, defended prey can succeed invasion even if it is introduced when their per capita growth rate is negative. The original full model (Eq. 1) shows qualitatively similar results with those of the quasiequilibrium assumption (Appendix C: Fig. C1). Note that the invasion timing also corresponds to the point on the limit cycle in the full model in Appendix C: Fig. C1B, D, and F.

What can we say about the propensity for the invasion success for a given timing and propagule size? Because this is an autonomous system (i.e., there is no 

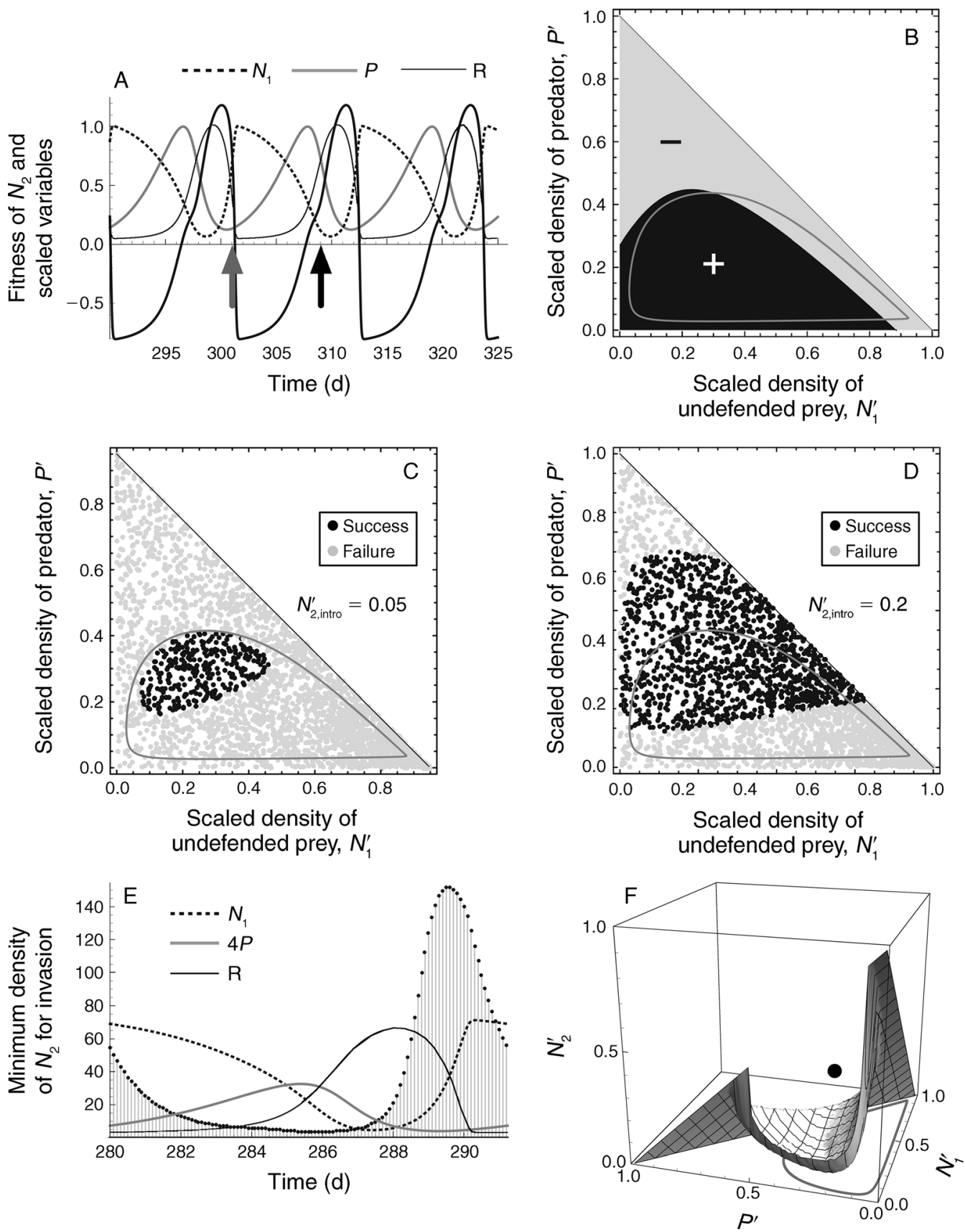

FIG. 2. (A) The per capita growth rate of defended prey $N_{2}\left(\left(1 / N_{2}\right)\left(d N_{2} / d t\right)\right)$ when it is rare (black thick line). Resource concentration $\left(R\right.$, black thin line), undefended prey density $\left(N_{1}\right.$, black dotted line), and predator density $(P$, gray line) are scaled to have a maximum value of 1 over the time period plotted. Black and gray arrows show the invasion timings in Fig. 1A and B, respectively. (B) The per capita growth rate ("+" is positive and "-" is negative growth rate) of rare defended prey $\left(N_{2}^{\prime}\right)$ in regard to scaled density of predators $\left(P^{\prime}\right)$ and undefended prey $\left(N_{1}^{\prime}\right)$. Scaling excludes resource $(R)$ from dynamics assuming the quasi-stable equilibrium. A gray orbit represents the limit cycle with undefended prey and predator. (C, D) Basins of attractions. The $x$ - and $y$-axes are scaled undefended prey density $\left(N_{1}^{\prime}\right)$ and predator density $\left(P^{\prime}\right)$. The gray circle is a trajectory of the limit cycle with undefended prey and predator. Gray points indicate the condition at which the invasion of defended prey fails, suggesting the basin of attraction of the limit cycle with undefended prey and predator. Black points indicate the conditions where the invasion of defended prey succeeds, suggesting another basin of attraction of the stable equilibrium with three species. The scaled invading prey density $\left(N_{2}^{\prime}\right.$.intro $)$ is 0.05 (C) or 0.2 (D). (E) Minimum defended prey density $N_{2}$ for invasion success at each phase of the cycle, where $t$ is days. (F) The phase-space representation of the dynamics, showing the surface separating the basins of attraction of the resident limit cycle and the invaded equilibrium. For better visualization of the 3-D structure, see Image E1 in Appendix E. Note that the sum of three variables is always smaller than one in the scaled model. 

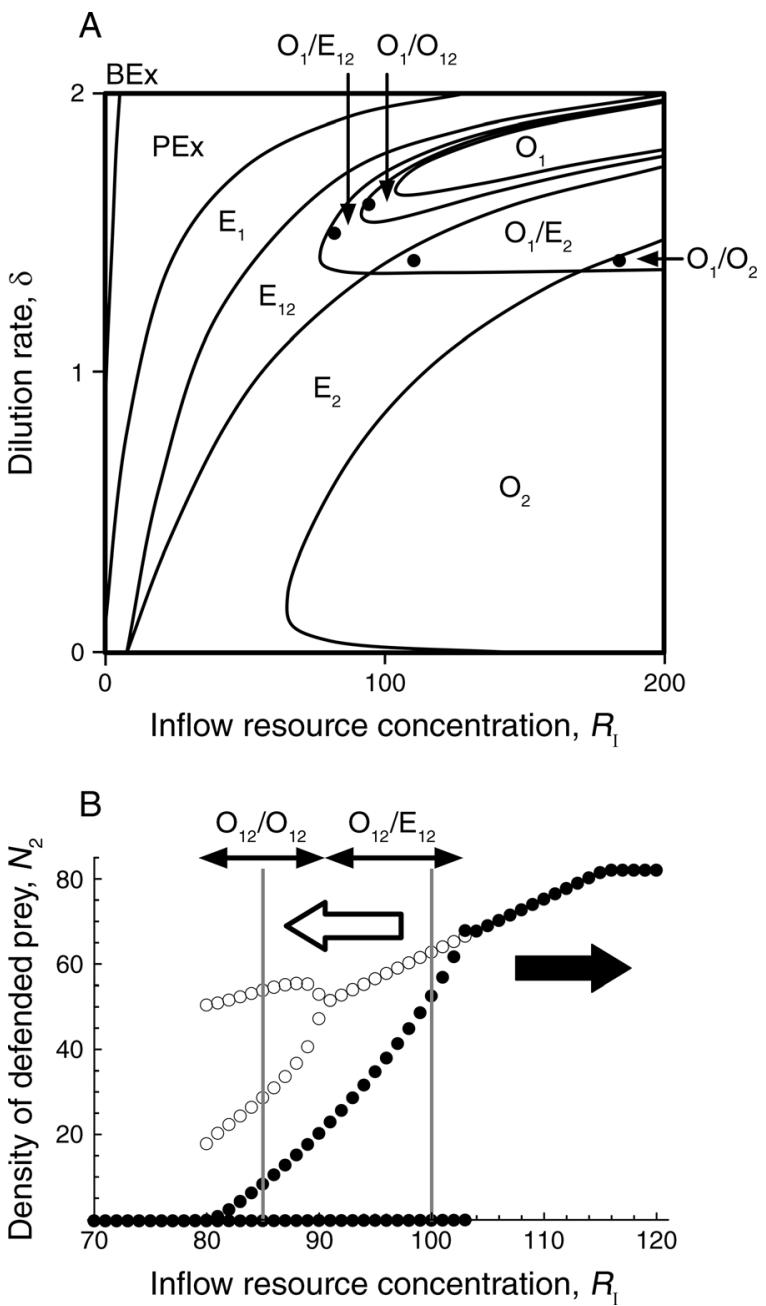

FIG. 3. (A) A phase diagram when $c_{2}=0.3$. The $x$ - and $y$ axes are inflow resource concentration $\left(R_{\mathrm{I}}\right)$ and dilution rate $(\delta)$. Parameter conditions indicated by black points in regions $\mathrm{O}_{1} / \mathrm{E}_{2}, \mathrm{O}_{1} / \mathrm{O}_{2}, \mathrm{O}_{1} / \mathrm{E}_{12}$, and $\mathrm{O}_{1} / \mathrm{O}_{12}$ correspond to the panels in Fig. 4. In region $\mathrm{BEx}$, both predator and prey go extinct; in region PEx, the predator goes extinct and the undefended prey persists in a stable equilibrium; in region $\mathrm{E}_{1}$, undefended prey and predator coexist in a stable equilibrium; in region $\mathrm{E}_{12}$, three species coexist in a stable equilibrium; in region $\mathrm{E}_{2}$, defended prey and predator coexist in a stable equilibrium; in region $\mathrm{O}_{1}$, undefended prey and predator coexist in a limit cycle; in region $\mathrm{O}_{12}$, three species coexist in a limit cycle; in region $\mathrm{O}_{2}$, defended prey and predator coexist in a limit cycle. (B) A bifurcation diagram when $c_{2}=0.2$ and $\delta=1.27$. The $x$-axis is inflow resource concentration $\left(R_{\mathrm{I}}\right)$ and the $y$-axis is defended prey maximum and minimum densities. The gray lines represent the parameter settings of panels $\mathrm{O}_{12} / \mathrm{E}_{12}$ and $\mathrm{O}_{12} / \mathrm{O}_{12}$ in Fig. 4. The solid circles are a continuation from the left side $\left(R_{\mathrm{I}}=70\right)$, and the open circles are from the right side $\left(R_{\mathrm{I}}=120\right)$. When inflow resource concentration is small, the system shows the limit cycle with predator and undefended prey $\left(\mathrm{O}_{1}\right)$, whereas the system shows the stable equilibrium with three species $\left(\mathrm{E}_{12}\right)$ when inflow resource concentration is large. The black arrow indicates that the black points are continuation from left side $\left(R_{\mathrm{I}}=70\right)$, and the white arrow indicates that the white points are from right side $\left(R_{\mathrm{I}}=120\right)$. external forcing), the timing and the propagule size can be translated to a coordinate in four-dimensional state space, i.e., the set of values $\left(R, N_{1}, N_{2}, P\right)$. The vulnerability to a demographic regime shift (in this case the quantified measure for the invasion success) can then be quantified by the minimum distance, along the invading species density axis, from the attractor in the resident population to the boundary surface of basin of attraction. The vulnerability can be shown as a minimum defended prey density required for the invasion success along the limit cycle (i.e., a measure of ecological resilience sensu Beisner et al. 2003); see Fig. $2 \mathrm{E}$ and Appendix E: Fig. E1). The minimum density is small when predator is abundant whereas it is very large when undefended prey is increasing, which is in good agreement with the per capita growth rate of rare defended prey (Fig. 2A). To understand the combined effects of timing and propagule size of invasion, the phase space representation is also useful in the scaled model with three variables and the boundary between the two basins of attraction is shown in Fig. $2 \mathrm{~F}$ (Appendix E: Image E1). The distance between the basin boundary and $N_{2}=0$ hyperplane (on which the limit cycle of the resident community exists) varies across the resident community phase space. Note that there are parts of the phase space where invasion of defended prey is possible with a very small propagule size, but the resident community dynamics (a gray orbit) never visits there (Fig. 2F). As parameters change, both the resident dynamics and the location of the basin boundary shift, which results in various bifurcations (see Multistability).

\section{Multistability}

We changed inflow resource concentration $\left(R_{\mathrm{I}}\right)$ from 0 to 200 and dilution rate $(\delta)$ from 0 to 2 when the capturing efficiency of defended prey $\left(c_{2}\right)$ is fixed 0.3 (Fig. 3A). We also changed inflow resource concentration from 70 to 120 by fixing $\delta=1.27$ and $c_{2}=0.2$ (Fig. $3 \mathrm{~B})$. Then we found broad bistable regions when the inflow resource concentration is intermediate-to-high and the dilution rate is high (Fig. 3). In total, we found six types of bistability in our model by bifurcation analysis (Table 1, Fig. 4). Note that the bistabilities 1b, $2 b$, and $3 b$ appear when the internal equilibrium in the bistabilities 1a, 2a, and 3a (E) loses local stability, respectively, leading to the limit cycle $(\mathrm{O})$ by Hopf bifurcation. Defended prey can exist when predator abundance is relatively stable (i.e., when predator density is in a stable equilibrium or in a limit cycle with small amplitudes), whereas undefended prey tends to be dominant in the system when predator density is in a limit cycle with large amplitudes (compare attractors with defended prey and without defended prey for the bistabilities 1a, 1b, 2a, and $2 \mathrm{~b}$ in Fig. 4).

The dynamics where both the timing and the propagule size of invasion determine its success are observed not only in the bistability 2a (Figs. 1, 2), but 
TABLE 1. Bistabilities in a predator-prey model (Eq. 1).

\begin{tabular}{|c|c|c|c|c|}
\hline Bistability & Abbreviation & Locally stable state 1 & Locally stable state 2 & Illustration \\
\hline 1a & $\mathrm{O}_{1} / \mathrm{E}_{2}$ & $\begin{array}{l}\text { undefended prey and predator limit } \\
\text { cycle }\end{array}$ & defended prey and predator equilibrium & Appendix D: Fig. D1 \\
\hline $1 b$ & $\mathrm{O}_{1} / \mathrm{O}_{2}$ & $\begin{array}{l}\text { undefended prey and predator limit } \\
\text { cycle }\end{array}$ & defended prey and predator limit cycle & Figs. D2, D3 \\
\hline $2 \mathrm{a}$ & $\mathrm{O}_{1} / \mathrm{E}_{12}$ & $\begin{array}{l}\text { undefended prey and predator limit } \\
\text { cycle }\end{array}$ & three-species equilibrium & Figs. 1,2 \\
\hline $2 b$ & $\mathrm{O}_{1} / \mathrm{O}_{12}$ & $\begin{array}{l}\text { undefended prey and predator limit } \\
\text { cycle }\end{array}$ & $\begin{array}{l}\text { three-species limit cycle with small } \\
\text { amplitude }\end{array}$ & Fig. D4 \\
\hline $3 \mathrm{a}$ & $\mathrm{O}_{12} / \mathrm{E}_{12}$ & $\begin{array}{l}\text { three-species limit cycle with large } \\
\text { amplitude }\end{array}$ & three-species equilibrium & Fig. D5 \\
\hline $3 b$ & $\mathrm{O}_{12} / \mathrm{O}_{12}$ & $\begin{array}{l}\text { three-species limit cycle with large } \\
\text { amplitude }\end{array}$ & $\begin{array}{l}\text { three-species limit cycle with small } \\
\text { amplitude }\end{array}$ & Figs. 5, 6, D6 \\
\hline
\end{tabular}

also in the bistabilities 1a, 1b, and 2b (Appendix D: Figs. D1-D4). In the bistabilities $1 \mathrm{a}$ and $1 \mathrm{~b}$, invasion success of exotic defended prey causes extinction of native undefended prey. Moreover, in the bistability $1 \mathrm{~b}$, it is possible to examine the invasibility of undefended prey to the native community with defended prey and predator as well. We found that undefended prey can invade when predator is scarce (Appendix A: Fig. A4, Appendix D: Fig. D3) and both invasion timing and propagule size influenced its invasion success, as in the case when defended prey is invading (Appendix A: Fig. A3, Appendix D: Fig. D2).

The bistabilities $3 \mathrm{a}\left(\mathrm{O}_{12} / \mathrm{E}_{12}\right)$ and $3 \mathrm{~b}\left(\mathrm{O}_{12} / \mathrm{O}_{12}\right)$ only contain coexisting attractors with three species, thus the limit cycle with only undefended prey and predator (a gray orbit in Fig. 5C) is locally unstable against the introduction of defended prey (Fig. 5), unlike the bistability case $2 \mathrm{a}$. Therefore, invasion of defended prey succeeds irrespective of introduced timing and the number of introduced individuals. However, if defended prey invades when predator is abundant, defended prey soon increases and dominates the system in a stable equilibrium in the bistability 3 a (Appendix D: Fig. D5) or in a limit cycle with small amplitude in the bistability 3b (Fig. 5A and Appendix D: Fig. D6). If defended prey invades when predator is scarce, on the other hand, defended prey can coexist with undefended prey, but the population cycle has large amplitudes in the bistabilities $3 \mathrm{a}$ and $3 \mathrm{~b}$ (Figs. 5B and Appendix D: Figs. D5, D6). The two limit cycles in the bistability 3b are significantly different if we consider the total prey density. In the three species limit cycles with small amplitude, the oscillation phase lag between predator and total prey is a half period (out-of-phase or antiphase; Fig. 6A) rather than an ordinary quarter period, especially at bifurcation points (Yoshida et al. 2003, Jones and Ellner 2007). On the other hand, the phase lag between predator and prey is not antiphase (quarter phase lag) in the limit cycles with large amplitude (Fig. 6B). This difference has an important implication for eco-evolutionary dynamics (see Discussion: Invasion timing and antiphase cycles).

\section{Discussion}

We proposed a possible synthesis of the two important hypotheses of invasion biology, propagule size and niche opportunity, by regarding invasion as a demographic regime shift with a time-varying threshold. Previous studies underlined the importance of invasion history (i.e., timing and sequence of invasion) in the formation of community structures (community assembly), considering the potential role of alternative stable states (ASS) and an Allee effect in invasion process (Chase 2003, Kadowaki et al. 2012). However, studies on the catastrophic regime shift have mainly considered alternative stable equilibria that are tractable analytically by assuming linear functional responses of species (Ives et al. 2008, Steiner et al. 2012). We, on the other hand, focus on the role of diverse population dynamics including alternative stable limit cycles in invasion processes. We found that ASS with limit cycles can cause an important and distinguished consequence in biological invasion.

We found several patterns of bistabilities in a predator-prey model with the Holling type II functional response, which is thought to be common for various predators, and this type of model was used for describing predator-prey systems in chemostats in previous studies (Yoshida et al. 2003, 2007, Meyer et al. 2006, Becks et al. 2010). The same model as ours was analyzed by Jones and Ellner (2007) and Yoshida et al. (2007), which however, did not capture all the bistabilities we observed here, probably because of the different trade-off assumed in the model (Appendix B: Fig. B1). The bistabilities in our system seem related to positive feedbacks between direct resource competition and apparent competition between two prey species (Holt 1977), and the demographic regime shift in our model is crucially influenced by interactions between the invading species and resident community. We found that the attractor dominated by defended prey shows a stable equilibrium or a limit cycle with smaller amplitudes, in contrast to the attractor dominated by undefended prey that shows a limit cycle with large amplitudes (Fig. 4). Therefore, when defended prey is dominant, predation 

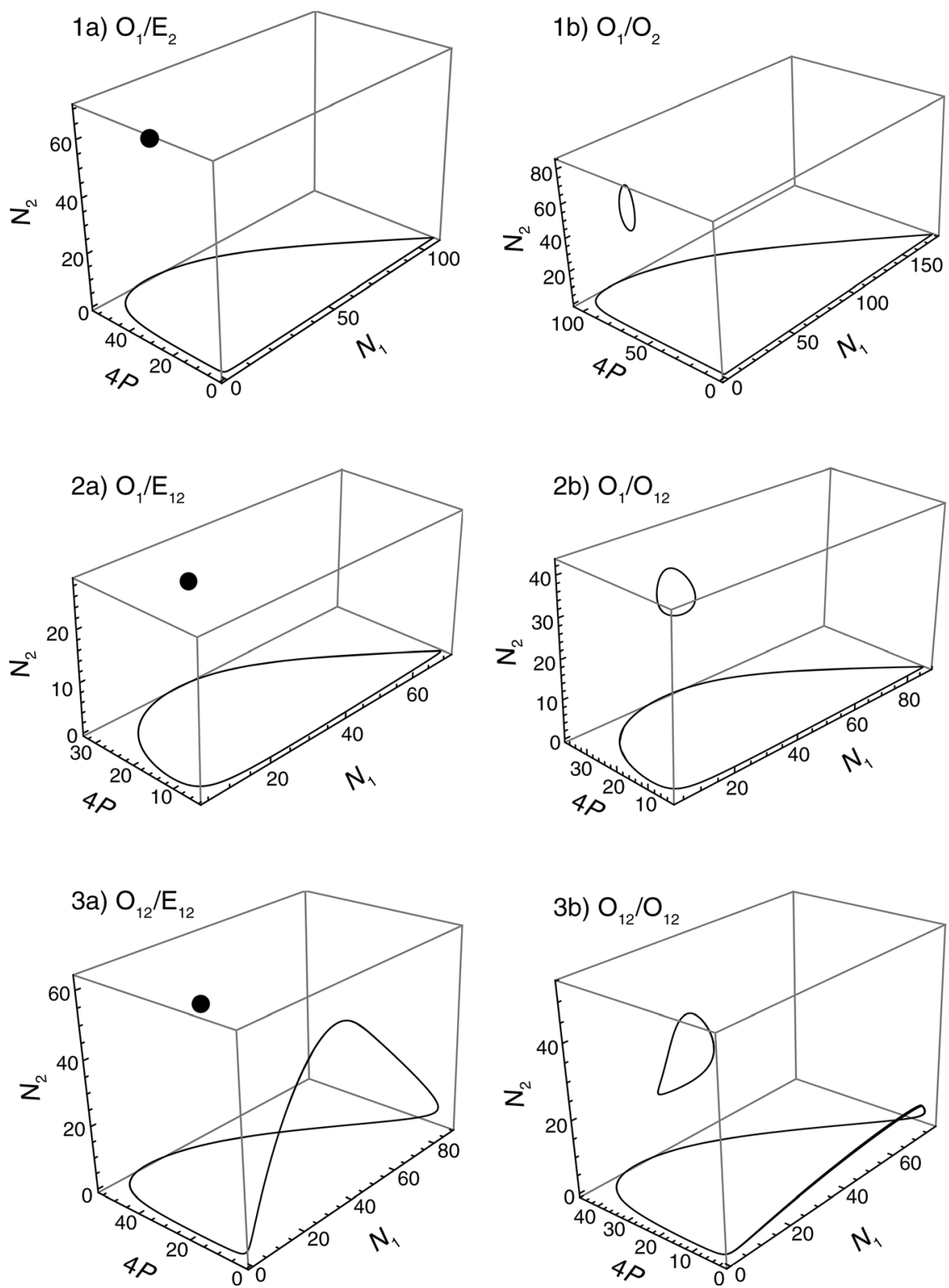

FIG. 4. Bistabilities in a predator-prey model. The $x$ - and $y$-axes are four times predator density $(4 P)$ and undefended prey density $\left(N_{1}\right)$, and the $z$-axis is defended prey density $\left(N_{2}\right)$. (1a) $\mathrm{O}_{1} / \mathrm{E}_{2}$, undefended prey cycle and defended prey equilibrium $\left(c_{2}=\right.$ $\left.0.3, \delta=1.4, R_{\mathrm{I}}=110\right)$. (1b) $\mathrm{O}_{1} / \mathrm{O}_{2}$, undefended prey cycle and defended prey cycle $\left(c_{2}=0.3, \delta=1.4, R_{\mathrm{I}}=180\right)$. (2a) $\mathrm{O}_{1} / \mathrm{E}_{12}$, undefended prey cycle and three-species equilibrium $\left(c_{2}=0.3, \delta=1.5, R_{\mathrm{I}}=80\right)$. (2b) $\mathrm{O}_{1} / \mathrm{O}_{12}$, undefended prey cycle and threespecies cycle with small amplitudes $\left(c_{2}=0.3, \delta=1.6, R_{\mathrm{I}}=95\right)$. (3a) $\mathrm{O}_{12} / \mathrm{E}_{12}$, three-species cycle with large amplitudes, and threespecies equilibrium $\left(c_{2}=0.2, \delta=1.27, R_{\mathrm{I}}=100\right)$. (3b) $\mathrm{O}_{12} / \mathrm{O}_{12}$, three-species cycles with large and small amplitudes $\left(c_{2}=0.2, \delta=\right.$ $\left.1.27, R_{\mathrm{I}}=85\right)$. The solid circles are the stable equilibria, and the open outlines are trajectories of the limit cycles.

pressure is relatively stable, which likely results in higher fitness of defended prey. On the other hand, when undefended prey is dominant, the time period of high predation pressure is relatively short so that the slowly growing defended prey finds it hard to increase. We suspect this kind of positive feedback as the cause of the bistabilities. It is already known that one predator-two prey models with the Holling type II functional response can typically show various multistabilities (Grover and Holt 1998, McCann et al. 1998, Abrams 1999, Vayenas and Pavlou 1999, Křivan and Eisner 2006). Therefore, multistability seems a general property of the predatorprey model with the type II functional response irrespective of the parameter values (see also the predator-prey model with logistic growth of prey in Appendix A and Figs. A1-A5, where we found similar bifurcations and multistabilities), and this multistability is what makes propagule size (and, if limit cycle is involved, invasion timing) important for invasion process. 
When the stable attractor of resident community is a limit cycle rather than a steady state, the invasion timing can largely affect subsequent settlement success as we see in our model. We found six kinds of bistabilities, and in four of them (1a, 1b, 2a, and 2b) invasion of a prey species occurred as a demographic regime shift (Fig. 4). When the system shows a limit cycle, the distance from the border of basins of attraction to the trajectory of attractor (i.e., ecological resilience, Beisner et al. 2003) changes through time (Fig. 2E and Appendix E: Fig. E1). Therefore, if a new species is introduced to the resident community when the border is close, invasion is possible with a sufficient number of individuals (Fig. 1). Previous theoretical studies on invasion timing usually focused on resource fluctuation, assuming environmental forcing (Namba and Takahashi 1993, Schoolmaster and Snyder 2007, but see Caplat et al. 2010) and complicated models (Schoolmaster and Snyder 2007, Caplat et al. 2010), but our model is simple and autonomous (no external forcing). Therefore, in our model, invasibility is an emergent property of the system (Davis et al. 2000) by interactions between predation and competition (Chase et al. 2002), and the window of invasibility can be easily understood in the state space (Fig. 2). By doing so, we found that a time-varying threshold of demographic regime shift is one of the fundamental mechanisms for niche opportunity.

Although a time-varying regime shift was important for understanding invasion success in a diamond food web we studied, it can be important in general as well. Indeed, our analyses on the predator-prey model with logistic growth of prey (Appendix A and Figs. A1-A5) and the Lotka-Volterra competition model with fluctuating carrying capacities (Appendix F and Fig. F1; Namba and Takahashi 1993) showed that the dependence of invasion success on both invasion timing and propagule size due to the time-varying threshold of demographic regime shift. Previous studies underlined the importance of an Allee effect on biological invasion because a strong demographic Allee effect can create ASS and make propagule size determine establishment success (Taylor and Hastings 2005, Drake and Lodge 2006, Takimoto 2009). Mechanisms of an Allee effect include predation (Gascoigne and Lipcius 2004), predator avoidance, and cooperative foraging (Taylor and Hastings 2005). Because predation pressure and resource availability often fluctuate temporally (Shea and Chesson 2002), a time-varying Allee effect can potentially be prevalent, and therefore both propagule size and timing of invasion can be commonly important for establishment success.

Our results have important implications for conservation ecology, as the two important hypotheses of biological invasion can be synthesized. For example, it would be difficult to understand the invasion process based on the dose-response curve of propagule size alone (Lockwood et al. 2005) if there is no unique curve due to the effect of invasion timing as our model
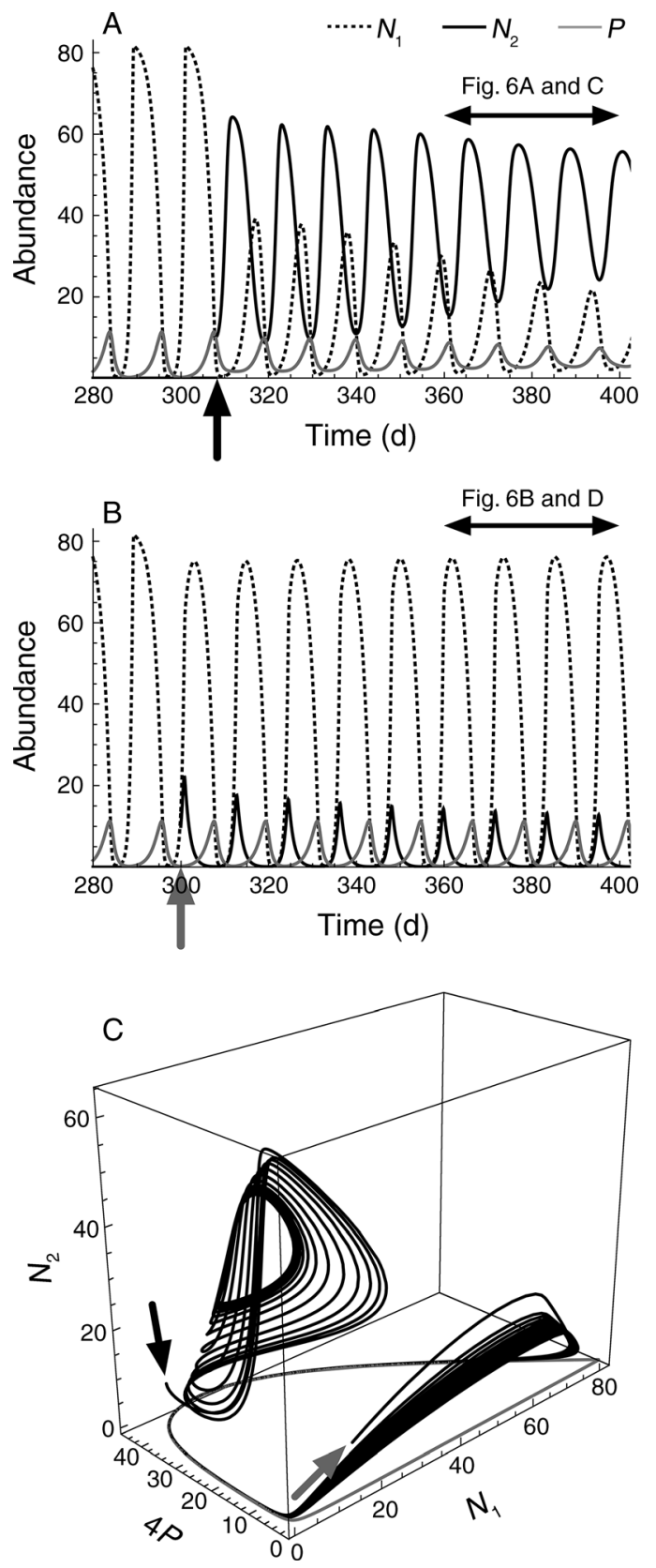

FIG. 5. (A) Antiphase cycles occurring after the introduction of defended prey at $t=308$ (black arrow), where $t$ is days. The black line represents $N_{2}$, the gray line represents $P$, and the dotted line represents $N_{1}$. (B) Nonantiphase cycles after the introduction of defended prey at $t=300$ (gray arrow), where $t$ is days. (C) Bistability between three-species limit cycles with small and large amplitudes $\left(N_{2, \text { intro }}=10, c_{2}=0.2, \delta=1.27, R_{\mathrm{I}}=\right.$ $85)$. The $x$ - and $y$-axes are four times predator density $(4 P)$ and undefended prey density $\left(N_{1}\right)$, respectively, and the $z$-axis is defended prey density $\left(N_{2}\right)$. Black and gray arrows represent the invasion timings shown in panels (A) and (B), respectively. A gray orbit represents the limit cycle with undefended prey and predator. 

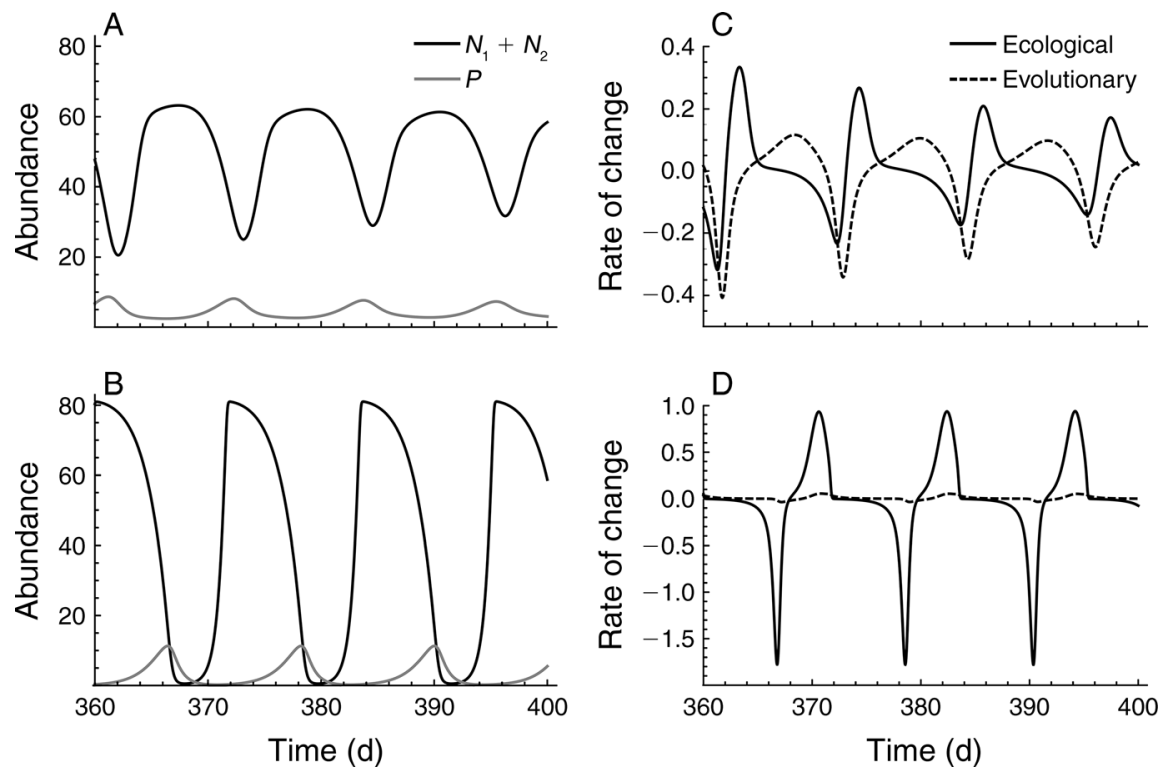

FIG. 6. (A) Antiphase cycles occurring after the introduction of defended prey at $t=308$ (Fig. 5A). (B) Nonantiphase cycles after the introduction of defended prey at $t=300$ (Fig. 5B). Gray lines represent the predator $(P)$; black lines are total prey $\left(N_{1}+\right.$ $N_{2}$ ). (C, D) The ecological (solid line) and evolutionary (dashed line) effects on the per capita growth rate of predator, given by the two terms on the right-hand side of Eq. G.1 in Appendix G. In all panels, $t$ is days.

suggested. Instead, the dose-response curve changes along the limit cycle and takes different patterns as shown in Fig. 2E and Appendix E: Fig. E1. Here, as our model is deterministic, the establishment probability is either 0 or 1 , and the minimum defended prey density for the establishment probability to become 1 is plotted along the cycle of the native community with undefended prey and predator. Also, even when the fitness of new species is temporarily positive (Fig. 2A, B), enough numbers of individuals are necessary for successful invasion (Fig. 2C, D). There is a body of literature on invasion into fluctuating communities based on the analyses using Lyapunov exponents (or long-term average marginal log-transformed growth rate of an invading species; Ferriere and Gatto 1995), and they also found that invasion success would not depend on whether the growth rate was initially positive or negative. Invasion from an infinitesimal propagule depends on a Lyapunov exponent evaluated along the entire orbit of the resident community. See also Chesson and Ellner (1989) for the use of Lyapunov exponents as invasibility criteria in fluctuating environments. On the other hand, our study and previous studies on niche opportunity suggest that the invading population can grow fast enough that it moves out of the realm of linear invasion dynamics depending on invasion timing, which is not evaluated by the method using the Lyapunov exponents. Previous theoretical studies found that adding weak trophic interactions (i.e., defended prey species) to an unstable community can stabilize its dynamics (Kretzschmar et al. 1993, McCann et al. 1998), but our study implies that invasion of defended prey is not always possible (Fig. 1). Stability of a community is often discussed in terms of the eigenvalues of coexistence equilibrium, but our study confirmed that bistability can sometimes prevent the community from moving to the stable coexistence equilibrium. These insights on the roles of invasion timing and propagule size will be useful not only for alien species control, but also for decisionmaking in reintroduction of a native but already extinct population (Caplat et al. 2010). In reintroduction trials, ideally, fitness of the introduced species should be maximized by carefully choosing a season or a phase of population dynamics, with a sufficiently large number of individuals. In addition to the introduction timing, we should be careful about the fitness after introduction, because positive per capita growth rate of introduction timing does not always ensure subsequent establishment success (Fig. 2). However, we suggest that multiple introductions (high propagule number) will be more practical as it can increase the chance to introduce populations at appropriate timing and to perturb limit cycles (as Fig. 1B) possibly making a future regime shift easier to occur.

\section{Invasion timing and antiphase cycles}

In the bistability $3 \mathrm{~b}$, we found that introduction timing of defended prey affects the oscillation phase lag between predator and total prey (Figs. 5,6). This is relevant to eco-evolutionary dynamics because the antiphase cycles are regarded as evidence of rapid evolution. Recent studies have revealed that a genetic change can occur rapidly enough to have a measurable impact on simultaneous ecological change in the wild (Hairston et al. 2005). Feedbacks between ecological and evolutionary dynamics are termed as the newest 
synthesis and are now intensively studied in ecology and evolutionary biology (Matthews et al. 2011, Schoener 2011). Yoshida et al. (2003) demonstrated that rapid evolution of prey defense can cause the antiphase cycle, whereas prey populations with a single genotype show an ordinary quarter period phase lag. Actually the antiphase cycle was studied by the same model as ours; note that the defense polymorphism of prey species in our model (Eq. 1) is interpreted as either different species or intraspecific clonal genotypes (Jones and Ellner 2007, Yoshida et al. 2007, Yamamichi et al. 2011). Previous studies have shown that the antiphase cycles are not generated by inducible defense (Cortez 2011) or other factors (Shertzer et al. 2002), therefore the antiphase cycles are regarded as evidence of rapid evolution (Hiltunen et al., in press). Those studies compared the effects of presence or absence of genetic variation on ecological dynamics, but few studies considered how genetic variation is arising (Fukami et al. 2007), although Yoshida et al. (2007) reported that the spontaneous appearance of a resistant genotype of bacteria can lead to a qualitative change in population dynamics in a bacteria-phage system (Figs. 6E and $\mathrm{F}$ in Yoshida et al. 2007). To understand the effect of introduction timing on eco-evolutionary dynamics, we calculated the contribution of ecological and evolutionary dynamics to a response variable (Hairston et al. $2005)$ in the antiphase and nonantiphase cycles. Measured by the impact on predator per capita growth as the response variable, evolutionary effects/ecological effects is 1.5 for antiphase cycles and 0.048 for nonantiphase cycles (Appendix G; see Fig. 6). Therefore, even when undefended and defended prey coexist and genotypic frequencies are changing by predation (i.e., rapid evolution is present), we may not see the smoking gun of rapid evolution (as shown by Jones and Ellner 2007), depending on introduction timing of genetic variation. Our results suggest that closer look at generating processes of genetic diversity will deepen our understanding of eco-evolutionary dynamics.

\section{ACKNOWLEDGMENTS}

We thank S. P. Ellner, N. G. Hairston, Jr., H. Ohtsuki, two anonymous reviewers, and members of the Ellner lab and the Hairston lab for their helpful comments. M. Yamamichi was supported by a Research Fellowship of the Japan Society for the Promotion of Science (JSPS) for Young Scientists (21-7611) and is supported by JSPS postdoctoral fellowship for research abroad (24-869). T. Yoshida acknowledges supports from JST, PRESTO, and JSPS KAKENHI Grant Number 19687002 and 20370009. A. Sasaki acknowledges a Grant-in-Aid for Scientific Research from JSPS and support from Graduate University for Advanced Studies (Sokendai).

\section{Literature Cited}

Abrams, P. A. 1999. Is predator-mediated coexistence possible in unstable systems? Ecology 80:608-621.

Allington, G. R. H., D. N. Koons, S. K. Morgan Ernest, M. R. Schutzenhofer, and T. J. Valone. 2013. Niche opportunities and invasion dynamics in a desert annual community. Ecology Letters 16:158-166.
Baiser, B., G. J. Russell, and J. L. Lockwood. 2010. Connectance determines invasion success via trophic interactions in model food webs. Oikos 119:1970-1976.

Becks, L., S. P. Ellner, L. E. Jones, and N. G. Hairston, Jr. 2010. Reduction of adaptive genetic diversity radically alters eco-evolutionary community dynamics. Ecology Letters 13: 989-997.

Beisner, B. E., D. T. Haydon, and K. Cuddington. 2003. Alternative stable states in ecology. Frontiers in Ecology and the Environment 1:376-382.

Caplat, P., M. Anand, and C. Bauch. 2010. Modelling invasibility in endogenously oscillating tree populations: timing of invasion matters. Biological Invasions 12:219-231.

Catford, J. A., R. Jansson, and C. Nilsson. 2009. Reducing redundancy in invasion ecology by integrating hypotheses into a single theoretical framework. Diversity and Distributions 15:22-40.

Chase, J. M. 2003. Community assembly: when should history matter? Oecologia 136:489-498.

Chase, J. M., P. A. Abrams, J. P. Grover, S. Diehl, P. Chesson, R. D. Holt, S. A. Richards, R. M. Nisbet, and T. J. Case. 2002. The interaction between predation and competition: a review and synthesis. Ecology Letters 5:302-315.

Chesson, P. L., and S. Ellner. 1989. Invasibility and stochastic boundedness in monotonic competition models. Journal of Mathematical Biology 27:117-138.

Cortez, M. H. 2011. Comparing the qualitatively different effects rapidly evolving and rapidly induced defenses have on predator-prey interactions. Ecology Letters 14:202-209.

Davis, M. A., J. P. Grime, and K. Thompson. 2000. Fluctuating resources in plant communities: a general theory of invasibility. Journal of Ecology 88:528-534.

Drake, J. M., and D. M. Lodge. 2006. Allee effects, propagule pressure and the probability of establishment: risk analysis for biological invasions. Biological Invasions 8:365-375.

Ermentrout, B. 2002. Simulating, analyzing, and animating dynamical systems: a guide to XPPAUT for researchers and students. Society for Industrial and Applied Mathematics, Philadelphia, Pennsylvania, USA.

Ferriere, R., and M. Gatto. 1995. Lyapunov exponents and the mathematics of invasion in oscillatory or chaotic populations. Theoretical Population Biology 48:126-171.

Fridley, J. D., J. J. Stachowicz, S. Naeem, D. F. Sax, E. W. Seabloom, M. D. Smith, T. J. Stohlgren, D. Tilman, and B. Von Holle. 2007. The invasion paradox: reconciling pattern and process in species invasions. Ecology 88:3-17.

Fukami, T., H. J. E. Beaumont, X. X. Zhang, and P. B. Rainey. 2007. Immigration history controls diversification in experimental adaptive radiation. Nature 446:436-439.

Fussmann, G. F., S. P. Ellner, K. W. Shertzer, and N. G. Hairston, Jr. 2000. Crossing the Hopf bifurcation in a live predator-prey system. Science 290:1358-1360.

Gascoigne, J. C., and R. N. Lipcius. 2004. Allee effects driven by predation. Journal of Applied Ecology 41:801-810.

Godoy, O., F. Valladares, and P. Castro-Díez. 2011. Multispecies comparison reveals that invasive and native plants differ in their traits but not in their plasticity. Functional Ecology 25:1248-1259.

Grover, J. P., and R. D. Holt. 1998. Disentangling resource and apparent competition: realistic models for plant-herbivore communities. Journal of Theoretical Biology 191:353-376.

Hairston, N. G., Jr., S. P. Ellner, M. A. Geber, T. Yoshida, and J. A. Fox. 2005. Rapid evolution and the convergence of ecological and evolutionary time. Ecology Letters 8:11141127.

Hairston, N. G., Sr., F. E. Smith, and L. B. Slobodkin. 1960. Community structure, population control, and competition. American Naturalist 94:421-425.

Hiltunen, T., N. G. Hairston, Jr., G. Hooker, L. E. Jones, and S. P. Ellner. In press. A newly discovered role of evolution in previously published consumer-resource dynamics. Ecology 
Letters. http://onlinelibrary.wiley.com/doi/10.1111/ele. 12291/abstract

Holt, R. D. 1977. Predation, apparent competition, and the structure of prey communities. Theoretical Population Biology 12:197-229.

Holt, R. D., J. Grover, and D. Tilman. 1994. Simple rules for interspecific dominance in systems with exploitative and apparent competition. American Naturalist 144:741-771.

Ives, A. R., Á. Einarsson, V. A. A. Jansen, and A. Gardarsson. 2008. High-amplitude fluctuations and alternative dynamical states of midges in Lake Myvatn. Nature 452:84-87.

Jones, L. E., and S. P. Ellner. 2007. Effects of rapid prey evolution on predator-prey cycles. Journal of Mathematical Biology 55:541-573.

Kadowaki, K., B. D. Inouye, and T. E. Miller. 2012. Assemblyhistory dynamics of a pitcher-plant protozoan community in experimental microcosms. PLoS One 7:e42651.

Kendall, B. E., J. Prendergast, and O. N. Bjørnstad. 1998. The macroecology of population dynamics: taxonomic and biogeographic patterns in population cycles. Ecology Letters $1: 160-164$.

Klausmeier, C. A., and E. Litchman. 2012. Successional dynamics in the seasonally forced diamond food web. American Naturalist 180:1-16.

Kretzschmar, M., R. M. Nisbet, and E. McCauley. 1993. A predator-prey model for zooplankton grazing on competing algal populations. Theoretical Population Biology 44:32-66.

Krivan, V., and J. Eisner. 2006. The effect of the Holling type II functional response on apparent competition. Theoretical Population Biology 70:421-430.

Leibold, M. A. 1996. A graphical model of keystone predators in food webs: trophic regulation of abundance, incidence, and diversity patterns in communities. American Naturalist 147:784-812.

Li, W., and M. H. H. Stevens. 2012. Fluctuating resource availability increases invasibility in microbial microcosms. Oikos 121:435-441.

Lockwood, J. L., P. Cassey, and T. Blackburn. 2005. The role of propagule pressure in explaining species invasions. Trends in Ecology and Evolution 20:223-228.

MacArthur, R. H., and E. O. Wilson. 1967. The theory of island biogeography. Princeton University Press, Princeton, New Jersey, USA.

Matthews, B., et al. 2011. Toward an integration of evolutionary biology and ecosystem science. Ecology Letters 14:690701.

McCann, K., A. Hastings, and G. R. Huxel. 1998. Weak trophic interactions and the balance of nature. Nature 395: 794-798.

McPeek, M. A. 1996. Trade-offs, food web structure, and the coexistence of habitat specialists and generalists. American Naturalist 148:S124-S138.

Meyer, J. R., S. P. Ellner, N. G. Hairston, Jr., L. E. Jones, and T. Yoshida. 2006. Prey evolution on the time scale of predator-prey dynamics revealed by allele-specific quantita- tive PCR. Proceedings of the National Academy of Sciences USA 103:10690-10695.

Namba, T., and S. Takahashi. 1993. Competitive coexistence in a seasonally fluctuating environment II. Multiple stable states and invasion success. Theoretical Population Biology 44: 374-402.

Noonburg, E. G., and J. E. Byers. 2005. More harm than good: when invader vulnerability to predators enhances impact on native species. Ecology 86:2555-2560.

Scheffer, M., S. Carpenter, J. A. Foley, C. Folke, and B. Walker. 2001. Catastrophic shifts in ecosystems. Nature 413: 591-596.

Schoener, T. W. 2011. The newest synthesis: understanding the interplay of evolutionary and ecological dynamics. Science $331: 426-429$.

Schoolmaster, D. R., Jr., and R. E. Snyder. 2007. Invasibility in a spatiotemporally fluctuating environment is determined by the periodicity of fluctuations and resident turnover rates. Proceedings of the Royal Society B 274:1429-1435.

Shea, K., and P. Chesson. 2002. Community ecology theory as a framework for biological invasions. Trends in Ecology and Evolution 17:170-176.

Shertzer, K. W., S. P. Ellner, G. F. Fussmann, and N. G. Hairston, Jr. 2002. Predator-prey cycles in an aquatic microcosm: testing hypotheses of mechanism. Journal of Animal Ecology 71:802-815.

Simberloff, D. 2009. The role of propagule pressure in biological invasions. Annual Review of Ecology, Evolution, and Systematics 40:81-102.

Steiner, C. F., C. A. Klausmeier, and E. Litchman. 2012. Transient dynamics and the destabilizing effects of prey heterogeneity. Ecology 93:632-644.

Takimoto, G. 2009. Early warning signals of demographic regime shifts in invading populations. Population Ecology 51:419-426.

Taylor, C. M., and A. Hastings. 2005. Allee effects in biological invasions. Ecology Letters 8:895-908.

Vandermeer, J. 2006. Oscillating populations and biodiversity maintenance. BioScience 56:967-975.

Vayenas, D. V., and S. Pavlou. 1999. Chaotic dynamics of a food web in a chemostat. Mathematical Biosciences 162:6984.

Williamson, M., and A. Fitter. 1996. The varying success of invaders. Ecology 77:1661-1666.

Yamamichi, M., T. Yoshida, and A. Sasaki. 2011. Comparing the effects of rapid evolution and phenotypic plasticity on predator-prey dynamics. American Naturalist 178:287-304.

Yoshida, T., S. P. Ellner, L. E. Jones, B. J. M. Bohannan, R. E. Lenski, and N. G. Hairston, Jr. 2007. Cryptic population dynamics: rapid evolution masks trophic interactions. PLoS Biology 5:1868-1879.

Yoshida, T., L. E. Jones, S. P. Ellner, G. F. Fussmann, and N. G. Hairston, Jr. 2003. Rapid evolution drives ecological dynamics in a predator-prey system. Nature 424:303-306.

\section{Supplemental Material}

\section{Appendix A}

Examples of the predator-prey model with logistic growth of prey (Ecological Archives E095-204-A1).

\section{Appendix B}

Effects of the trade-off between defense and growth in defended prey on bistability (Ecological Archives E095-204-A2). 


\section{Appendix D}

Effects of invasion timing and propagule size in the bistabilities 1a, 1b, 2b, 3a, and 3b of the chemostat model (Ecological Archives E095-204=A4).

\section{Appendix E}

Three-dimensional views of the time-varying dose-response curve and the phase space representation (Ecological Archives E095-204-A5).

\section{Appendix F}

Examples of the simple Lotka-Volterra model (Ecological Archives E095-204-A6).

\section{Appendix G}

Comparing ecological and evolutionary dynamics in the bistability 3b (Ecological Archives E095-204-A7). 